\title{
Retirement-from-sport considerations following pediatric sports-related concussion: case illustrations and institutional approach
}

\author{
Michael J. Ellis, MD, FRCSC, ${ }^{1,2,6-9}$ Patrick J. McDonald, MD, MHSc, FRCSC, ${ }^{8-11}$ \\ Dean Cordingley, MSc, ${ }^{7,9}$ Behzad Mansouri, MD, PhD, FRCP(C), 4,7,9 \\ Marco Essig, MD, PhD, FRCP(C), ,7,9 and Lesley Ritchie, PhD $5,7,9$
}

\begin{abstract}
Departments of ${ }^{1}$ Surgery, ${ }^{2}$ Pediatrics and Child Health, ${ }^{3}$ Diagnostic Radiology, ${ }^{4}$ Neurology and Neuro-ophthalmology, and ${ }^{5} \mathrm{Clinical}$ Health Psychology, and ${ }^{6}$ Section of Neurosurgery, University of Manitoba; ${ }^{7}$ Pan Am Concussion Program; ${ }^{8} \mathrm{Children's}$ Hospital Research Institute of Manitoba; ${ }^{9}$ Canada North Concussion Network, Winnipeg, Manitoba; ${ }^{10}$ Division of Neurosurgery, British Columbia Children's Hospital; and ${ }^{11}$ University of British Columbia, Vancouver, British Columbia, Canada
\end{abstract}

\begin{abstract}
The decision to advise an athlete to retire from sports following sports-related concussion (SRC) remains a persistent challenge for physicians. In the absence of strong empirical evidence to support recommendations, clinical decision making must be individualized and should involve a multidisciplinary team of experts in concussion and traumatic brain injury. Although previous authors have advocated for a more conservative approach to these issues in child and adolescent athletes, there are few reports outlining considerations for this process among this unique population. Here, the authors use multiple case illustrations to discuss 3 subgroups of clinical considerations for sports retirement among pediatric SRC patients including the following: those with structural brain abnormalities identified on neuroimaging, those presenting with focal neurological deficits and abnormalities on physical examination, and those in whom the cumulative or prolonged effects of concussion are suspected or demonstrated. The authors' evolving multidisciplinary institutional approach to return-to-play and retirement decision making in pediatric SRC is also presented.
\end{abstract}

http://thejns.org/doi/abs/10.3171/2016.1.FOCUS15600

KEY WORDS concussion; traumatic brain injury; neuropsychology; neuroimaging; return to play; retirement

$\mathrm{S}$ PORTS-RELATED concussion is a form of traumatic brain injury (TBI) that affects millions of North Americans annually. ${ }^{27,60,73}$ Historically, SRC has been viewed as a functional disturbance of cerebral metabolism and blood flow that results in temporary alterations in neurological functioning that resolve within 7-10 days. ${ }^{68,69}$ More recently, however, increasing attention has focused on the more serious effects of concussion and subconcussive injuries including abnormalities documented on advanced structural neuroimaging studies and the longterm risk of developing cognitive impairment, mood disorders, and neurodegenerative diseases including chronic traumatic encephalopathy (CTE). ${ }^{7,29,44,48,49,51,65,70,71,80,94,98,99}$

To mitigate the risks of more serious brain injury following SRC, experts offer consensus statements containing supervised return-to-play (RTP) guidelines that promote the safe return of athletes to the field of play after concussion symptoms have fully resolved.,68,69 These guidelines may reduce the risk of second-impact syndrome, a very rare and poorly defined condition thought to arise from loss of cerebral autoregulation and resultant diffuse cerebral edema. ${ }^{67}$ However, they do not provide direction as to whether athletes should be advised to avoid future contact and collision sports because of the risk of adverse short- and long-term outcomes associated with future concussion. Over the years, several authors have offered recommendations about when athletes should be advised to retire from contact or collision sports, but most have focused on collegiate and professional athletes. ${ }^{16,18,}$ $20,21,23,43,66,76,91,93$ Although some authors suggest a more conservative approach should be applied to child and adolescent athletes, ${ }^{16,23}$ indications for retirement from sports remain controversial and there are limited reports that discuss these issues in application to pediatric SRC patients. Because decisions regarding athlete retirement are complex and must be tailored to the individuals in the absence

ABBREVIATIONS CTE = chronic traumatic encephalopathy; $\mathrm{PCS}=$ postconcussion syndrome; $\mathrm{RTP}=$ return to play; $\mathrm{SCl}=$ spinal cord injury; SCIWORA = SCI without radiographic abnormality; $\mathrm{SRC}=$ sports-related concussion; $\mathrm{TBI}$ = traumatic brain injury.

SUBMITTED November 27, 2015. ACCEPTED January 29, 2016.

INCLUDE WHEN CITING DOI: 10.3171/2016.1.FOCUS15600. 
of evidence-based guidelines, it is important for multidisciplinary concussion centers to share their experience with patients presenting with indications for sport retirement.

Here we discuss 3 important subgroups of clinical considerations pertaining to sport retirement for pediatric SRC patients. These are patients with structural brain abnormalities identified on neuroimaging, those presenting with focal neurological deficits and abnormalities on physical examination, and those in whom the cumulative or prolonged effects of concussion are suspected or demonstrated. Three cases are presented to help illustrate our evolving multidisciplinary institutional approach to these unique patients.

\section{General Considerations}

The decision to advise an athlete to retire from competitive sports is among the greatest challenges facing physicians who care for athletes with SRC. Retirement from sport decision making must be approached on an individualized basis, taking into consideration important factors such as age; sex; medical and concussion history; sport; position and level of play; severity, type, and duration of concussion symptoms; neuroimaging and neuropsychological testing results; and natural history and outcome data for coexisting neurological disorders. Ultimately, in making these decisions we must weigh the risk of future injury against the potential negative consequences of discontinuing sport. Although the clinical decision-making process regarding retirement/RTP for collegiate and professional athletes may need to consider other social and legal factors such as a loss of income or scholarship and suitability to perform other occupations, ${ }^{43,93}$ the process when children are involved requires a more conservative approach that is based solely on the future health of the patient. As these decisions are often more complex than typical RTP decisions, ideally, they should involve a multidisciplinary team of experts with clinical training in pediatric TBI, a team in which each member offers complementary expertise from within his/her clinical training and practice. In our opinion, neurosurgeons play an important role in retirement decision making following SRC because they are the health care professionals with the highest level of clinical training in the diagnosis and management of structural nervous system injuries that can accompany head and spine trauma. Neuropsychologists also play an integral role in the management of this unique population because they are the only health care professionals trained to administer and interpret formal neuropsychological testing instruments that are often the only tools capable of detecting subtle evidence of persistent functional brain injury. In certain circumstances, input from other professionals with specialized training in neurological disorders, such as neurologists, neuro-ophthalmologists, and orthopedic spine surgeons, can also be valuable. Because RTP decisions are often made in the absence of firm empirical evidence, the experience of the multidisciplinary team plays a pivotal role in arriving at clinical recommendations. Importantly these cases can have medicolegal implications for the treating physician and team, so it is imperative that the clinical decision-making process places the highest value on preserving the long-term health and neurological functioning of the athlete. It must be acknowledged that the approach described here is not firm rules but represents a conceptual framework that can be modified based on individual patient factors and must incorporate new research findings as they become available.

\section{Structural Brain Abnormalities Illustrative Case 1}

A 13-year-old boy with a history of insomnia and no previous head injuries sustained a head injury that was associated with a loss of consciousness while playing dodgeball during gym class. Immediately after the patient's head hit the gym floor, he displayed convulsions involving the right upper and lower extremities, and following the convulsions he experienced a 5-minute period of rightsided weakness. The patient was evaluated at an outside emergency department where he underwent brain CT that demonstrated a 3.4- $\mathrm{mm}$ focal hyperdensity in the left frontoparietal white matter suspicious for a small intraparenchymal hemorrhage. Brain MRI performed 5 months later demonstrated a left frontoparietal focus of gliosis with associated hemosiderin deposition, confirming the presence of an intraparenchymal hemorrhage (Fig. 1A and B). The patient was referred to the pediatric concussion program 8 months postinjury. At that time, he complained of chronic low-grade headaches that had been present since the head injury; were not associated with any aura, photophobia, or nausea; and were not exacerbated by physical or cognitive activity. The patient had continued to play hockey despite ongoing headaches. There were no further seizures reported and findings on physical examination were normal. The clinical picture was in keeping with an initial SRC and posttraumatic seizure, as well as ongoing posttraumatic headaches. Based on the presence of a structural abnormality detected on neuroimaging, we advised the patient to avoid future contact sports and referred the patient to a pediatric neurologist for management of posttraumatic headaches and further workup of his posttraumatic seizure.

\section{Discussion}

Historically, SRC has been considered a metabolic or functional brain injury that occurs in the absence of structural damage to the brain. In rare cases, however, traumatic forces applied to the head and spine during sporting activities can result in more serious central and peripheral nervous system injuries that can be detected on clinical neuroimaging. In other cases, neuroimaging studies can reveal structural brain abnormalities that can have an important impact on RTP and retirement decision making.

Some authors have suggested that any athlete with a traumatic abnormality detected on neuroimaging be considered for sport retirement. ${ }^{16,17,93}$ Traumatic injuries documented on neuroimages of athletes with sports-related head injuries range in severity from nondisplaced basal and calvarial skull fractures, to cerebral contusions, to life-threatening subdural hematomas and diffuse cerebral edema. ${ }^{115}$ In the pediatric population, evidence-based clinical decision rules have been devised to help guide the 

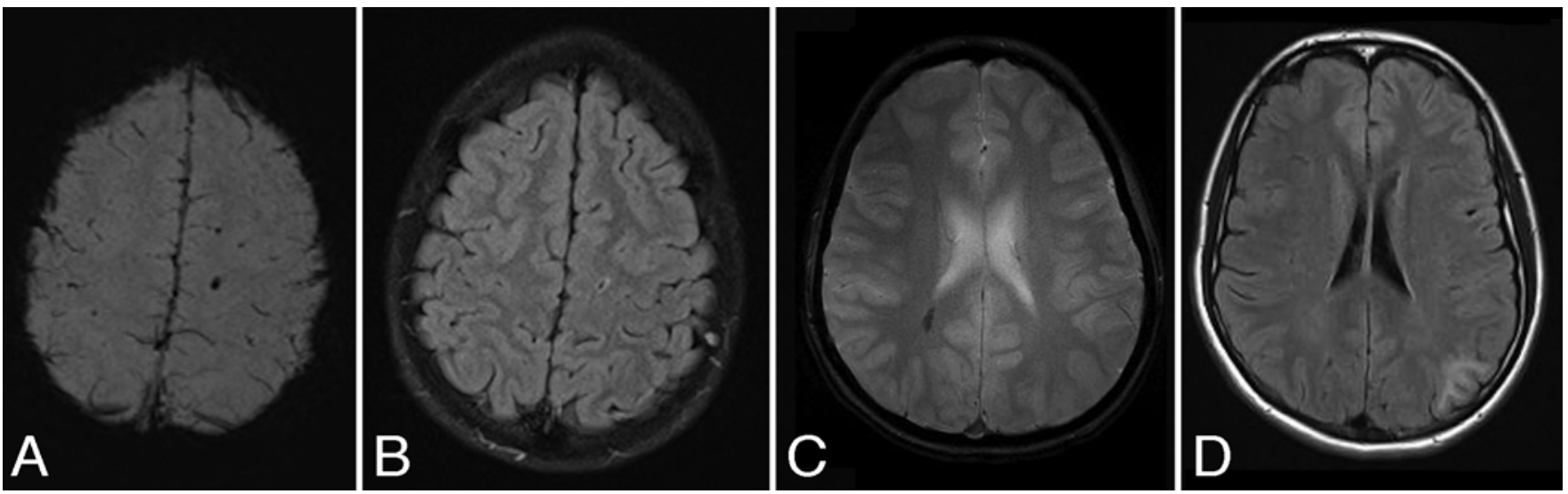

FIG. 1. Traumatic structural brain abnormalities identified on neuroimaging in patients with SRC. Axial susceptibility-weighted (A) and FLAIR (B) MR images obtained in a 13-year-old boy presenting with posttraumatic seizure and right-sided Todd's paralysis after he sustained a concussion playing dodgeball, demonstrating focal left frontal intraparenchymal hemorrhage. Axial gradient recalled echo MR image $(\mathbf{C})$ acquired in an 11-year-old boy presenting with persistent headaches following hockey-related concussion, demonstrating intraparenchymal hemorrhage within the occipital white matter. Axial FLAIR MR image (D) obtained in a 14-year-old girl presenting with formal neuropsychological deficits following Ringette-related concussion. Features are consistent with nonhemorrhagic intraparenchymal contusion. All patients were advised to retire from contact and collision sports based on imaging findings. Panels C and D are reproduced from Ellis et al.: J Neurosurg Pediatr 16:241-247, 2015. Published with permission.

judicious use of CT scanning in the emergency room setting. ${ }^{58,82}$ In contrast, evidence-based guidelines for the use of MRI, which avoids being exposed to ionizing radiation, in the evaluation and management of pediatric SRC patients are lacking. At present, expert consensus guidelines suggest that clinical MRI studies add little value to the evaluation of concussion patients but should be considered in patients with persistently altered level of consciousness (which is rare in sports injury) and those with focal neurological deficits and persistent symptoms, the duration of which is not well defined and can vary across age groups. ${ }^{69}$ More recently, advancements in MRI techniques such as gradient recalled echo and susceptibility-weighted imaging that are more sensitive to iron-containing blood products have facilitated enhanced detection of microhemorrhages in children with moderate and severe TBI, but there are few studies that have examined the added clinical value of these sequences in pediatric SRC. ${ }^{5,9,103}$ In a small retrospective study at our institution, we detected traumatic abnormalities in $11 \%$ of pediatric SRC patients who underwent clinical neuroimaging, including 2 patients with a nondisplaced calvarial skull fracture and orbital fracture demonstrated on CT and 2 patients with an intraparenchymal hemorrhage and nonhemorrhagic contusion demonstrated on MRI (Fig. 1C and D). ${ }^{38}$

Because clinical neuroimaging studies show normal findings in the vast majority of SRC patients, recent studies have applied numerous advanced neuroimaging techniques to this population including diffusion tensor imaging, task-based and resting-state functional MRI, resting cerebral blood flow imaging, and cerebrovascular reactivity mapping. ${ }^{36,79,114}$ Although they have increased our insight into this condition, at present, none of the aforementioned techniques has advanced beyond research use to impact the routine clinical management of individual concussion patients.
Patients who have undergone craniotomy represent an important patient population who must be carefully considered for retirement from sports. Some authors suggest that any athlete who has undergone a craniotomy for evacuation of any intracranial hemorrhage should be considered for retirement, ${ }^{93}$ while others suggest that athletes with subdural and epidural hematomas may be considered for RTP if the patient has normal findings on neurological examination, brain reexpansion, and radiographic evidence of bone flap healing. ${ }^{28,76}$ One survey-based study of the American Association of Neurological Surgeons included 32 patients who underwent craniotomy, the vast majority (approximately 80\%) of whom returned to sports between 3 months and 1 year postinjury. ${ }^{91}$

In addition to traumatic abnormalities, some authors have suggested that patients found to have other congenital and acquired structural abnormalities of the brain, including arachnoid cysts, hydrocephalus, cavum septum pellucidum, and Chiari malformations, should also be considered for sport retirement. ${ }^{16,23,76,93}$ Arachnoid cysts arise from CSF accumulation within layers of the arachnoid and are a common incidental finding on neuroimaging. ${ }^{1}$ In some cases, children with arachnoid cysts have been found to present with intraarachnoid cyst hemorrhage, subdural hematoma, or hygroma following sportsrelated head injury. ${ }^{31,52,87,110}$ Bleeding associated with arachnoid cysts is thought to arise from fragile vessels within the cyst wall or bridging veins. ${ }^{76}$ One recent retrospective study suggested that arachnoid cyst diameter of $5 \mathrm{~cm}$ or more was associated with a higher risk of hemorrhage/rupture in children. ${ }^{26}$ Hydrocephalus accounts for an estimated 69,000 hospital discharges per year in the United States ${ }^{11}$ and is most commonly treated with ventriculoperitoneal shunting or endoscopic third ventriculostomy. ${ }^{55}$ In one survey of members of the Joint Section on Pediatric Neurosurgery of the American Association of 
Neurological Surgeons and the Congress of Neurological Surgeons, the rate of shunt-related complications among pediatric hydrocephalus patients participating in sports was exceedingly low $(<1 \%)$ but may include shunt malfunction, damage to shunt hardware, and subdural fluid collections and hematomas. ${ }^{10}$ Of pediatric neurosurgeons surveyed in this study, one-third advised against participation in all contacts sports, one-third advised against participation in selected sports, and one-third did not impose restrictions on sports participation. Cavum septum pellucidum is a normal congenital variant that is a common incidental finding on neuroimaging in children and can persist in up to $20 \%$ of adults. ${ }^{111}$ Some authors have suggested that a cavum septum pellucidum is an absolute contraindication to return to sports ${ }^{16}$ because of its previously observed association with other neuropathological and neuroimaging findings in patients with repeated head injury, while others have suggested that isolated cavum septum pellucidum should not preclude contact sports participation. ${ }^{76}$ Finally, several authors have suggested that patients with symptomatic or pain-causing lesions at the level of the foramen magnum, including Chiari malformations, be considered for retirement from contact and collision sports. ${ }^{20,76,93}$ These recommendations largely stem from rare reports of sudden death among patients with Chiari malformations exposed to minor head trauma, and from speculation that medullary compression could have accounted for these outcomes. ${ }^{76} \mathrm{~A}$ recent retrospective cohort study, however, demonstrated an exceedingly low risk of future catastrophic injury during sports participation in children with Chiari I malformation, even after foramen magnum decompression..$^{72}$ Taken together, arachnoid cysts, cavum septum pellucidum, and Chiari malformations are all relatively common incidental findings on neuroimaging, and, as such, it is likely that a large number of children playing contact sports have these lesions but do not know it.

In our institutional opinion, all patients with evidence of a structural abnormality on neuroimaging should undergo consultation with a neurosurgeon to discuss decision-making options for RTP and retirement. As little is known about the clinical and genetic factors that place athletes at risk for the potential long-term consequences of SRC, we view traumatic brain abnormalities detected on clinical neuroimaging (CT, conventional MRI including recalled echo and susceptibility-weighted imaging) as an absolute contraindication to allowing the patients to return to contact and collision sports, especially when the patients have clinical or neuropsychological evidence of abnormal brain function or if they have required neurosurgical intervention. We acknowledge that there is no empirical evidence to support this recommendation and that others have documented successful RTP for professional athletes who have sustained an intracranial hemorrhage. ${ }^{76}$ However, we believe pediatric patients warrant a more conservative approach and that there is little acceptable rationale to permitting a child or adolescent athlete with structural brain damage to return to an environment where the potential risk of additional injury exists. In our opinion, pediatric patients with basal and nondepressed calvarial skull fractures should be managed on an indi- vidualized basis and can often be returned to full sports participation after there is clinical and radiological evidence of fracture healing. Patients who have undergone previous craniotomy for nontraumatic lesions as well as those treated with endoscopic, endovascular, and transsphenoidal approaches are managed on an individualized basis and can often be returned to play without restriction. Because clinicopathological spectrum structural abnormalities such as Chiari malformation, arachnoid cyst, hydrocephalus, and septum pellucidum can present, we recommend patients with these conditions be managed by neurosurgeons on an individualized basis tailored to clinical and radiographic findings as well as available natural history data (Fig. 2). In our opinion, there is no empirical evidence to declare these conditions as absolute contraindications to safe contact sports participation in children and adolescents, but patients and their parents must be informed of rare reports of fatal and disabling outcomes related to RTP with these conditions (Table 1).

\section{Abnormalities on Physical Examination Illustrative Case 2}

A 16-year-old boy with a history of 3 previous concussions sustained a head injury when he was thrown from his bike during a competitive motocross event. This injury was associated with a 4-minute loss of consciousness and posttraumatic amnesia lasting into the following day. The patient was transferred to a pediatric trauma center where he underwent CT brain and cervical spine imaging that demonstrated no abnormalities. Following the resolution of posttraumatic confusion, the patient began to complain of headache as well as diplopia that was worse when he looked downward. At the time of consultation 2 days postinjury, he continued to complain of diplopia when looking downward but endorsed no other concussion symptoms. Physical examination revealed a left trochlear nerve palsy but no other abnormalities. Neuro-ophthalmology consultation confirmed a left traumatic trochlear nerve palsy that was treated with prism glasses. Brain MRI demonstrated no evidence of structural brain injury. Graded aerobic treadmill testing elicited no symptomlimiting threshold at a maximal blood pressure of 214/86 $\mathrm{mm} \mathrm{Hg}$ and maximal heart rate of $191 \mathrm{bpm}$ suggestive of physiological recovery. However, formal neuropsychological testing revealed deficits in complex auditory attention, phonemic fluency, retrieval of auditory information, in the presence of intact processing speed, visual reproduction, and visual memory. His neurocognitive profile was suggestive of a subcortical pattern of cognitive deficits secondary to TBI. At 3 months postinjury the patient's diplopia had resolved and neuro-ophthalmological follow-up confirmed clinical resolution of the trochlear nerve palsy. Although the patient expressed interest in returning to competitive motocross sports, the multidisciplinary team advised him to retire from contact, collision, and motocross sports primarily due to the potential risk of repeat and permanent cranial nerve injury associated with repeat head trauma. Repeat neuropsychological testing to monitor neurocognitive recovery following SRC was declined by the patient and his parent. 

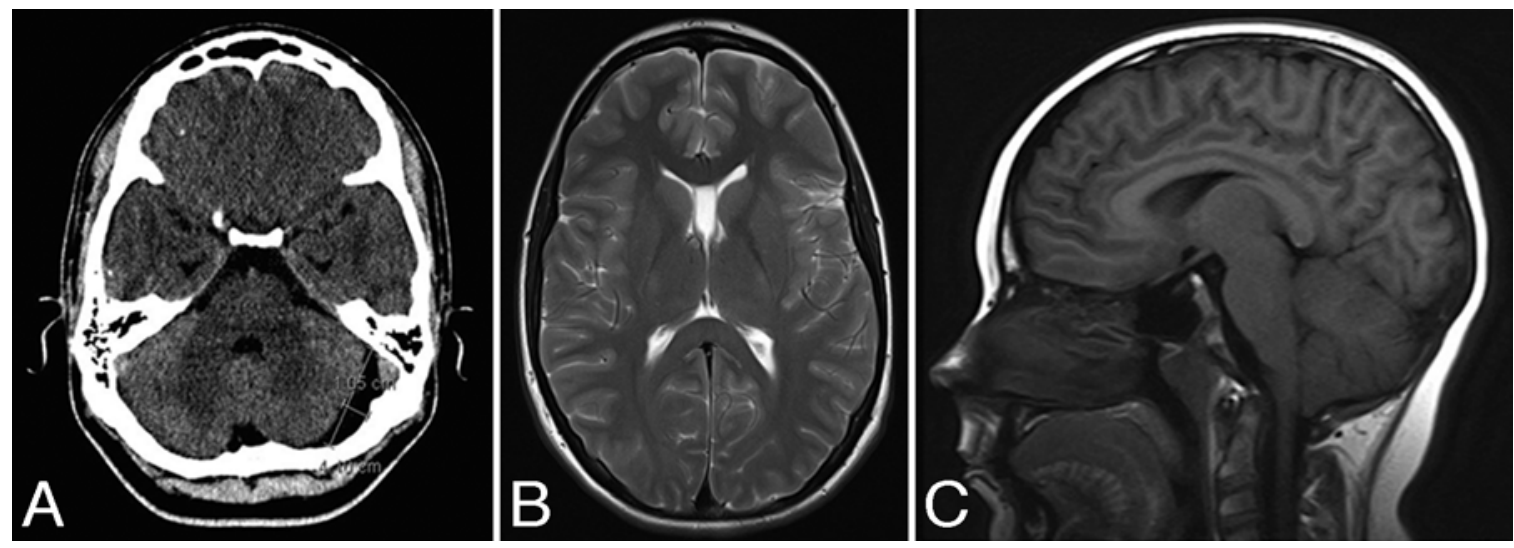

FIG. 2. Incidental structural brain abnormalities identified on neuroimaging in pediatric patients with sports-related concussion. A: Posterior fossa arachnoid cyst measuring $1.05 \times 4.10 \mathrm{~cm}$. B: Cavum septum pellucidum. C: Chiari I malformation with 7-mm tonsillar herniation below the level of the foramen magnum. All patients were returned to full sporting activities without restriction.

\section{Discussion}

Another important group of patients who should be considered for retirement from contact and collision sports are those who present with focal neurological deficits and abnormalities on physical examination. ${ }^{16}$ Unlike the majority of generalized concussion symptoms that reflect global alterations in cerebral metabolism and blood flow, ${ }^{45}$ focal neurological deficits often point to isolated damage or dysfunction within specific areas of the central or peripheral nervous system. Focal neurological deficits following SRC can often be localized by salient features of the clinical history and physical examination performed by a physician with clinical training in traumatic brain and spine injury. In this population, neuroimaging plays an important role not only in defining the extent of structural injury but also in the evaluation of other neurological disor- ders that can coexist with SRC and present with focal neurological deficits. ${ }^{38,113}$ Understanding the pathophysiology of focal neurological deficits following SRC not only is important to allow physicians to initiate prompt, evidencebased management of underlying neurological conditions but also can be helpful in minimizing the risk of future or recurrent brain and spine injuries. In our experience, focal neurological deficits following pediatric SRC most commonly present as coexisting cranial nerve, cervical spine, or peripheral nerve injuries.

Visual disturbance is common following TBI and SRC and can arise from structural or functional injury to the oculomotor, vestibular, and visual processing systems of the brain. Subjective and objective evidence of vestibuloocular dysfunction can manifest in the form of convergence insufficiency, and abnormalities of smooth pursuits,

TABLE 1. Summary of our current institutional approach to RTP and retirement considerations in children and adolescents with structural brain abnormalities

\begin{tabular}{|c|c|}
\hline Clinical Indication & Institutional Approach/RTP Consideration \\
\hline Traumatic structural brain injury & Retirement from future contact \& collision sports participation \\
\hline $\begin{array}{l}\text { Skull fractures \& prior craniotomy for nontraumatic brain } \\
\text { lesions }\end{array}$ & $\begin{array}{l}\text { Individualized approach. RTP considered following radiographic evidence of bone } \\
\text { healing }\end{array}$ \\
\hline $\begin{array}{l}\text { Craniotomy for traumatic lesions (e.g., subdural hematoma, } \\
\text { intraparenchymal hemorrhage, second-impact syndrome) }\end{array}$ & Retirement from future contact \& collision sports participation \\
\hline $\begin{array}{l}\text { Transsphenoidal, endovascular, endoscopic approaches to } \\
\text { intracranial lesions }\end{array}$ & Individualized approach \\
\hline Cavum septum pellucidum & No contraindication to safe RTP \\
\hline Arachnoid cyst & $\begin{array}{l}\text { Individualized approach. Patient must be informed of risk of intracystic hemorrhage, } \\
\text { subdural hematoma/hygroma. RTP considered in patients w/ small, asymptomatic, } \\
\text { or incidental arachnoid cysts }(<5 \mathrm{~cm}) \mathrm{w} / \text { no or minimal mass effect }\end{array}$ \\
\hline Hydrocephalus & $\begin{array}{l}\text { Individualized approach. Patient must be informed of risk of shunt malfunction, hard- } \\
\text { ware damage, subdural hematoma/hygroma. RTP considered in patients treated w/ } \\
\text { endoscopic third ventriculostomy }\end{array}$ \\
\hline Chiari Type I malformation & $\begin{array}{l}\text { Individualized approach. RTP considered for patients w/ asymptomatic or minimal } \\
\text { tonsillar herniation w/ no syrinx. RTP considered in patients w/ foramen magnum } \\
\text { decompression w/o associated spinal malformation \& instability }\end{array}$ \\
\hline
\end{tabular}


saccades, and the vestibuloocular reflex that have been reported in 29\%-63\% of pediatric SRC patients. ${ }^{35}$ These deficits are proposed to be mediated by isolated functional impairment of the vestibular and oculomotor subsystems that often resolve spontaneously and can be addressed with targeted vestibular rehabilitation. 3,37,92 On the other hand, visual disturbance associated with traumatic cranial nerve injury following pediatric TBI occurs less commonly and can have a variable prognosis. Trauma is the most common cause of acquired oculomotor, trochlear, and abducens nerve palsies in children, who often present with blurred vision and diplopia. ${ }^{56}$ Traumatic optic neuropathy occurs in $0.5 \%-12 \%$ of TBI patients ${ }^{24,97}$ with approximately $20 \%$ of pediatric cases due to sports-related injuries..$^{42,46}$ The clinical presentation of traumatic optic neuropathy can vary from subtle monocular blurred vision or visual field deficits to complete blindness. All patients with suspected cranial nerve injuries affecting vision should be promptly referred to a neuro-ophthalmologist for comprehensive assessment. ${ }^{40}$ Although neuroimaging is commonly normal even in cases of severe cranial nerve deficits, these studies can also be helpful to rule out other conditions responsible for these deficits (neoplasm, inflammatory conditions, etc.). ${ }^{38}$ The prognosis of traumatic cranial nerve palsies is largely dependent on the severity of injury at initial presentation. Most patients with traumatic optic, oculomotor, trochlear, and abducens neuropathies that present with mild deficits improve with conservative management, while those with complete injuries rarely experience a complete recovery. ${ }^{42,46,63,88}$ Despite a relatively good prognosis, there are no evidence-based guidelines to help direct RTP and retirement decision making in these populations. Nevertheless, because of the potential risk of recurrent injury and the significant disability associated with permanent injury, it has been our institutional approach to recommend retirement from contact and collision sports in all pediatric SRC patients presenting with traumatic cranial nerve palsies even after clinical recovery has been achieved. ${ }^{40}$

Children and adolescents with SRC can also present with focal neurological deficits due to coexisting acute spinal cord injury (SCI), central cord neurapraxia, SCI without radiographic abnormality (SCIWORA), and nerve root/brachial plexus traction injuries. Distinguishing between these conditions requires a careful history, complete neurological and spine physical examination, and the appropriate use of neuroimaging that may include plain and dynamic radiography, CT, and MRI. Clinical presentation of pediatric SCIs can range from subtle unilateral motor or sensory deficits to complete quadriplegia. In some cases, children and adolescents can sustain injury to spinal column that presents with localized pain and decreased range of motion but without neurological deficit. Similar to RTP and retirement recommendations regarding SRC, guidelines for cervical spine injuries are also controversial and derived from retrospective studies of collegiate and professional adult athletes. Patients who sustain an acute SCI with evidence of a spinal cord structural injury are typically advised to retire from contact and collision sports. ${ }^{6}$ Adult patients with stable fractures without neurovascular injury can often be returned to full athletic competition after radiographic confirmation of bone healing, return of full and painless range of motion, and a normal neurological examination. ${ }^{85}$ In certain cases, retirement from contact sports should be considered; this would include retirement for individuals with atlantoaxial instability or fusion, and dynamic subaxial instability indicated by greater than $3.5 \mathrm{~mm}$ translation or greater than $11^{\circ}$ of angulation on radiographic imaging. ${ }^{2,6,85,112}$ Some authors have suggested that adult patients treated with 1-level anterior or posterior instrumented fusions can be cleared for RTP, with patients who have undergone multilevel instrumented fusions considered for sports retirement. ${ }^{19,85,108}$ Others have reported safe return to contact sports of patients with multilevel fusions and evidence of spinal cord signal change on MRI. ${ }^{101}$ Because these types of injuries are rare in children and adolescents and because RTP and retirement guidelines do not exist for these populations, we recommend that patients with confirmed structural cervical spine and spinal cord injuries be managed on an individualized basis by neurosurgeons and orthopedic surgeons with experience in pediatric spine injuries. In our opinion, children and adolescents who have sustained a structural SCI and those who have undergone spinal fusion with instrumentation should be considered for retirement from contact and collision sports.

In our experience, more common than patients presenting with fixed neurological deficits and structural SCI at the time of SRC are those who experience transient neurological deficits with variable clinical examination findings and normal imaging features. Again, distinguishing between underlying conditions in this setting depends on a careful assessment of the presenting symptoms; the location, nature, and duration of associated sensorimotor deficits; a history of previous neurological events, trauma, or spinal disorders; and complete neurological and spine examinations. Central cord neurapraxia, cervical SCIWORA, and nerve root/brachial plexus injuries are conditions that can present with transient focal neurological deficits and can coexist in patients with SRC. The clinical presentation of central cord neurapraxia and cervical SCIWORA can range from subtle neurological symptoms such as burning or tingling in one or both upper extremities to complete quadriplegia. Spinal canal stenosis, defined as a canal-body ratio of 0.8 or less, has been observed in up to $95 \%$ of reported cases of central cord neurapraxia. ${ }^{106}$ Owing to unique anatomical and biomechanical features of the developing spine, SCIWORA occurs predominantly in children and adolescents, accounting for $67 \%$ of traumatic spine injuries, with $43 \%$ of cases occurring during sporting activities..$^{12}$ In contrast, patients with "burners" or "stingers" typically present with unilateral burning pain that radiates from the neck down the arm in a dermatomal distribution, and these injuries can be associated with motor weakness of muscles innervated by the affected nerve root(s). Central cord neurapraxia is typically defined as the presence of myelopathic symptoms that resolve within 10 minutes to 48 hours of the injury, while symptoms of SCIWORA can persist for hours to weeks after injury. All patients with suspected central cord neurapraxia or SCIWORA should undergo structural imaging including MRI and plain and flexion-extension radiography, while 
the diagnosis of burners and stingers can usually be made clinically. Unlike central cord neurapraxia where symptoms resolve within 48 hours, the prognosis of SCIWORA is more variable and dependent on the severity of the initial neurological deficits ${ }^{81,84}$ and the presence of structural changes on MRI. ${ }^{83}$

Return-to-play recommendations for these 3 conditions also vary across sources. Some authors have suggested that athletes with a single episode of central neurapraxia can be safely returned to play as long there are no neurological deficits and no radiological evidence of SCI or spinal stenosis; ${ }^{104,109}$ however, those with a second episode should be advised to retire..$^{85,89,104}$ In one study, recurrent episodes of central cord neurapraxia in athletes returned to sporting activities occurred in $56 \%$ of cases, but no athlete suffered permanent neurological injury. ${ }^{105}$ Patients with central cord neurapraxia and MRI evidence of structural SCI are often advised to retire. ${ }^{6,104}$ Patients with asymptomatic or incidentally discovered cervical stenosis are often managed on an individualized basis and informed of the potential risk of SCI associated with a return to contact sports. ${ }^{19}$ RTP management in patients with SCIWORA remains controversial. Some authors have suggested that SCIWORA is associated with occult spinal instability that precludes a return to contact or collision sports, ${ }^{84,86}$ while others have suggested that there is insufficient evidence to support persistent spinal instability in this population. ${ }^{12}$ In patients presenting with nerve root/brachial plexus injuries, ${ }^{53}$ some authors have suggested that those with 1 or 2 episodes can be returned to play following complete resolution of symptoms and a normal neurological examination, ${ }^{107}$ whereas those with 3 or more episodes should be withheld from sports pending the results of cervical spine neuroimaging to rule out predisposing conditions (e.g., foraminal stenosis or disc herniation) and electrodiagnostic studies to confirm neurophysiological recovery. ${ }^{85}$

Because there is a lack of empirical evidence to guide clinical decision making, we view pediatric patients with transient or focal neurological deficits localized to the cervical spine and occurring in the absence of abnormalities on comprehensive imaging to represent a unique population whose care must also be individualized. In our experience, children and adolescents with coexisting SCIWORA who present with transient or subtle neurological deficits in the setting of a normal imaging workup can be returned to contact sports without increased risk of future injury. ${ }^{39}$ However, individuals with more severe and prolonged deficits and whose imaging workup demonstrates evidence of cervical spine stenosis (anteroposterior cervical canal diameter $<14 \mathrm{~mm}$, Torg ratio $<0.8$ ) or other congenital spine malformations that may confer a risk of instability (e.g., Type I Klippel-Feil syndrome, os odontoideum, atlantooccipital fusion, etc. $)^{104}$ should be considered for retirement from contact and collision sports (Fig. 3). Patients with coexisting nerve root/brachial plexus injuries must also be managed on an individualized basis following appropriate clinical and imaging evaluation to rule out structural cervical spine injuries. In all of these circumstances, patients and their parents must be informed of the elevated risk of recurrent injury with return to contact and collision sports (Table 2).
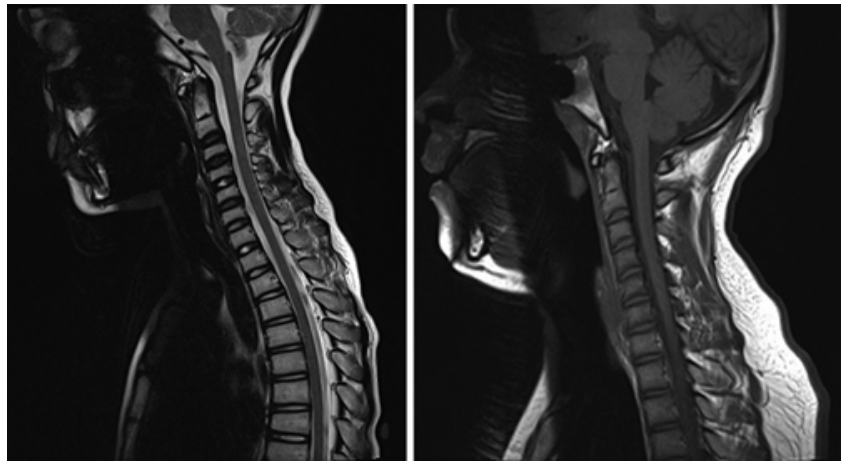

FIG. 3. SRC patients with coexisting SCIWORA and central cord neurapraxia. Left: Sagittal T2-weighted MR image obtained in a 13-year-old presenting with hockey-related concussion and 6 -week period of bilateral hand numbness and sensory deficit. The image demonstrates no evidence of $\mathrm{SCl}$, ligamentous injury, or spinal stenosis. This patient was successfully returned to contact sport (hockey) following symptom resolution, normal neurological examination, full and painless range of motion, and evidence of normal findings on flexion-extension radiographs without further injury. Right: Sagittal T2-weighted MR image acquired in a 17-year-old child with SRC and transient upper- and lower-extremity numbness and weakness following a tackle in football. The image demonstrates congenital cervical spinal stenosis (cross-sectional anteroposterior canal diameter at C-3 measuring $12 \mathrm{~mm}$ ) and loss of cervical lordosis. This patient with coexisting central cord neurapraxia and spinal stenosis was advised to retire from contact and collision sports due to elevated risk of future $\mathrm{SCl}$.

\section{Cumulative or Prolonged Effects of Concussion}

\section{Illustrative Case 3}

A 15-year-old boy with a history of migraine headaches and 2 prior SRCs sustained an injury from a head-to-head tackle during a football game; he did not lose consciousness or suffer posttraumatic amnesia. He underwent consultation at the pediatric concussion program 1 month postinjury, at which time he complained of headaches, dizziness, and difficulties with focusing, concentrating, and memory. His initial Post-Concussion Symptom Scale score $^{57}$ was 70. Initial physical examination revealed a near point of convergence of $10 \mathrm{~cm}$, symptomatic horizontal saccade testing, and impaired balance testing. The patient underwent aerobic treadmill testing, the results of which were consistent with a diagnosis of physiological postconcussion disorder, and brain MRI, for research purposes, revealed no structural injury. The patient's vestibuloocular dysfunction resolved spontaneously, and submaximal exercise was prescribed. Three months later the patient's symptoms had improved significantly (Post-Concussion Symptom Scale score of 15) and he underwent formal neuropsychological testing. Testing revealed deficits in complex attention span, divided attention, and encoding of unstructured auditory information in the setting of otherwise normal cognitive processing. The results were suggestive of cognitive changes secondary to concussion. The patient continued to be managed with submaximal aerobic exercise prescription and 5 months later underwent repeat treadmill and neuropsychological testing. At that time, 9 months postinjury the patient was capable of exercising to 
TABLE 2. Summary of our current institutional approach to RTP and retirement considerations for children and adolescents presenting with focal neurological deficits and physical examination abnormalities

\begin{tabular}{|c|c|}
\hline Indication & Institutional Approach/RTP Considerations \\
\hline Traumatic cranial neuropathy & Retirement from future contact \& collision sports participation \\
\hline Structural acute SCl & Retirement from future contact \& collision sports participation \\
\hline $\begin{array}{l}\text { Spinal column fractures w/o neurological deficit \& } \\
\text { spinal instrumentation }\end{array}$ & $\begin{array}{l}\text { Individualized approach. RTP considered for patients w/ radiographic evidence of fracture healing } \\
\text { \& spinal column stability, full \& painless range of cervical spine motion }\end{array}$ \\
\hline Spinal column fractures w/ spinal instrumentation & Retirement from future contact \& collision sports \\
\hline Central cord neurapraxia/SCIWORA & $\begin{array}{l}\text { Individualized approach. First event: RTP considered for children w/ mild \& short-duration symp- } \\
\text { toms \& normal neurological exam, full \& painless range of cervical spine motion, \& no evidence } \\
\text { of spinal stenosis or instability. Patients must be informed of increased risk of recurrent \& } \\
\text { potentially disabling injury. For patients w/ imaging evidence of spinal stenosis/spinal instability: } \\
\text { Retirement from future contact \& collision sports. Second event: Retirement from future contact } \\
\text { \& collision sports }\end{array}$ \\
\hline Asymptomatic or incidental cervical stenosis & $\begin{array}{l}\text { Individualized approach. Patients must be informed of increased risk of temporary neurological } \\
\text { deficits \& potentially disabling SCI }\end{array}$ \\
\hline Nerve root/brachial plexus injuries & $\begin{array}{l}\text { Individualized approach. First event: RTP considered in asymptomatic children w/ normal neuro- } \\
\text { logical exam. Patients must be informed of increased risk of recurrence in presence of forami- } \\
\text { nal stenosis. Second event: Retirement from future contact \& collision sports participation }\end{array}$ \\
\hline
\end{tabular}

exhaustion during treadmill testing and neuropsychological testing results had returned to normal. Because of the patient's concussion history and prolonged clinical course with associated objective cognitive deficits, the decision was made to proceed with retirement from competitive football.

\section{Discussion}

The most challenging group of patients to manage, from a retirement-from-sport perspective, are those who had prolonged symptoms and in whom the cumulative effects of multiple concussions are suspected or demonstrated. Over the past decade, mounting evidence suggests that concussions and subconcussive head injuries can have a cumulative effect on short- and long-term neurological health and functioning. In the short term, clinical research suggests that athletes with a history of concussions are significantly more likely to sustain future concussions ${ }^{50}$ and present with more severe symptoms. ${ }^{22}$ In the long term, some evidence suggests that retired professional football players with a history of repetitive head trauma are at an elevated risk of depression, mild cognitive impairment, and earlier onset of Alzheimer's disease. ${ }^{48,49,54}$ One study demonstrated an elevated risk of death due to Alzheimer's disease and amyotrophic lateral sclerosis among professional football players compared with a healthy population. ${ }^{62}$ Importantly, other authors have failed to identify alterations in cognitive functioning in collegiate athletes with multiple concussions. ${ }^{14}$ In addition to multiple concussions, research has begun to suggest that cumulative exposure to subconcussions, defined as "a cranial impact that does not result in known or diagnosed concussion," can lead to neurocognitive deficits and structural and functional brain abnormalities detected on advanced neuroimaging studies.? Chronic traumatic encephalopathy (CTE) is a neurodegenerative condition characterized neuropathologically by gross features such as enlarged lateral ventricles; a fenestrated cavum septum pellucidum; scarring of the cerebellar folia; atrophy most often affecting the frontal and medial temporal lobes, thalamus, hypothalamus, and mammillary bodies; and degeneration of the substantia nigra and locus coeruleus. Histological features include glial and neuronal deposition of hyperphosphorylated tau with a perivascular distribution or localization at the depths of cortical sulci. ${ }^{70,97}$ The clinical manifestations of chronic traumatic encephalopathy often present as 2 variants. ${ }^{96}$ Athletes with the cognitive variant present primarily with memory and executive function impairments, while those with the mood/behavioral variant often present with symptoms of depression and anxiety as well as aggressive, violent, or disinhibited behavior. To date, the majority of published cases of CTE have occurred in collegiate and professional athletes who have retired from careers in boxing, American football, and hockey; ${ }^{44,65}$ however, a limited number of cases of CTE have been also reported among adolescents with a history of repetitive head trauma. ${ }^{71}$ While some authors continue to point out the lack of empirical evidence supporting a causal relationship between TBI and CTE,,$^{29,44,94}$ there does appear to be empirical justification to actively limit individuals' exposure to concussions and subconcussive head injuries during a period of active brain development in children and adolescents.

Despite these concerns, there are no evidence-based guidelines that address how many total concussions are too many, how many concussions incurred in 1 season are too many, and what impact abnormalities on objective measures such as formal neuropsychological testing should have on retirement decision making. Historically, it was suggested that athletes who sustained 3 concussions associated with a loss of consciousness should take a season off before returning to sports. ${ }^{102}$ These recommendations were later incorporated into the Colorado Medical Society/American Academy of Neurology and Cantu 
grading systems to guide RTP decision making., 4,15,17,66 More recently, some authors have suggested that athletes be considered for retirement in the following scenarios: those who have sustained 3 or more concussions in 1 season, those who have sustained 2 major concussions in a season, those who have sustained 3 or more major concussions, those with evidence of a lowered threshold for concussions, those who developed objective evidence of impaired neuropsychological functioning, and those who exhibit symptoms of CTE. ${ }^{16,20,23,93}$ Although symptoms of CTE are rare among the pediatric SRC population, children and adolescents can develop postinjury psychiatric outcomes that are often multifactorial in etiology and can take the form of novel psychiatric disorders, isolated suicidal ideation, or worsening symptoms of a preinjury psychiatric disorder. ${ }^{41}$ To date, the majority of published case reports on the retirement decision-making process in the setting of multiple concussions and prolonged recovery are limited to discussions regarding collegiate and professional athletes. ${ }^{16,43}$

The RTP and retirement decision-making process regarding pediatric SRC patients with prolonged recovery is challenging due to our incomplete understanding of what constitutes a normal recovery in children and adolescents. Although most collegiate and professional athletes will achieve neurological and neurocognitive recovery within 1-2 weeks, the natural history of pediatric SRC remains poorly understood. Among studies of pediatric concussion patients, the median duration of symptoms varies from 25 to 75 days, ${ }^{13,25,35}$ with $21 \%-73 \%$ of patients reporting symptoms persisting greater than 1 month $25,34,47,75$ in duration and $2.3 \%$ reporting symptoms at 1 year postinjury. ${ }^{8}$ Because of the wide variability in mean recovery time following pediatric SRC in the literature, the distinction between a major and a minor concussion is not particularly relevant to this patient population. Clinical variables that may impact the likelihood of prolonged symptoms in concussion patients include younger age, female sex, loss of consciousness or posttraumatic amnesia at the time of injury, a history of concussion, attention-deficit hyperactivity disorder, learning disorder, mood disorders, delayed symptom onset, postinjury headache or dizziness, as well as symptom burden and subjective and objective evidence of vestibuloocular dysfunction at initial consultation. ${ }^{25,35,59,61,64,74,75,77}$

Overall, RTP and retirement decision making regarding pediatric patients with prolonged postconcussion syndrome (PCS; > 3-6 months) and multiple concussions must also be individualized. It is in this population that a multidisciplinary approach is most important and should always involve a clinical neuropsychologist who is the only health care professional with certified training in the administration, interpretation, and psychometrics of comprehensive neuropsychological testing. ${ }^{32,33,78,90}$ Even with a certified neuropsychologist, however, there is a paucity of evidence regarding how computerized neurocognitive and formal neuropsychological testing should be used in the pediatric SRC population. ${ }^{30}$ Neuroimaging can also be helpful to evaluate whether there are any structural findings that may contribute to a prolonged recovery or neuropsychological deficits. ${ }^{38}$ At present, there is insufficient empirical data to mandate sports retirement in pediatric patients based on the duration of PCS symptoms, total number of lifetime concussions, or number of concussions sustained over any given time period. There is also no empirical evidence to establish thresholds of concussions or subconcussive injuries that places children and adolescents at an elevated risk of developing mental health disorders, persistent neuropsychological deficits, or neurodegenerative conditions such as CTE. Given these knowledge gaps, the retirement discussion with pediatric SRC patients and their parents must acknowledge the lack of evidence upon which to base firm recommendations. Nonetheless, because there is some evidence that points to increased vulnerability to future and more severe concussions among athletes with previous concussions, we advise all pediatric SRC patients and their parents that sustaining a single SRC may place the child at an elevated risk of future concussions that can occur with less force and may lead to more prolonged symptoms. ${ }^{100}$ In our patients, those who sustain 2 or more concussions in a season and those who develop prolonged PCS (>3-6 months) are often strongly advised to take the rest of the season off of contact sports. In pediatric patients who have sustained 4 or more lifetime, physician-diagnosed concussions, we generally strongly consider contact sport retirement, with those patients with 3 concussions managed on an individualized basis. Patients who exhibit persistent neurocognitive deficits on objective neuropsychological testing are not cleared for return to sport until a return to full-time academic studies is achieved and a return to baseline cognitive functioning is identified. Those who develop postinjury psychiatric outcomes represent a unique population whose management must also be individualized. At present, it remains unclear whether the pathophysiological mechanisms mediating these outcomes represent an unrecovered TBI and place patients at an elevated risk of concussion if returned to play even if controlled on psychiatric medications. As such, we consider multiple factors including preinjury psychiatric history, severity of symptoms, and neuropsychological testing and neuroimaging results when making recommendations to these patients. Finally, because of the lack of evidence-based guidelines regarding sport retirement decision making and lack of a gold standard objective test to determine physiological concussion recovery, it is our clinical practice to perform graded aerobic treadmill testing and formal neuropsychological testing prior to returning the following to contact and collision sports: all pediatric patients with prolonged PCS ( $>3$ months), those who have sustained 2 or more concussions in a single season, those who have sustained 3 or more total concussions, and those who develop postinjury psychiatric disorders. Although we acknowledge that viewpoints may differ among concussion health care professionals and from center to center, we believe these recommendations represent a more conservative approach to treating child and adolescent patients and reflect the limitations of current empirical evidence (Table 3).

\section{Conclusions}

Decision making regarding RTP and retirement from sport remains a persistent challenge for physicians and 
TABLE 3. Summary of our current institutional approach to RTP and retirement considerations for children and adolescents with evidence of cumulative or prolonged effects of concussion

\begin{tabular}{|c|c|}
\hline Clinical Indication & Institutional Approach/RTP Considerations \\
\hline Two concussions in 1 season & $\begin{array}{l}\text { Strongly considered indication for season-ending retirement. Consider RTP during the following season follow- } \\
\text { ing symptomatic recovery, graded aerobic treadmill, \& formal neuropsychological testing }\end{array}$ \\
\hline Three lifetime & $\begin{array}{l}\text { Individualized approach. Consider RTP during the following season after symptomatic recovery, graded aerobic } \\
\text { treadmill, \& formal neuropsychological testing }\end{array}$ \\
\hline Four or more concussions & Individualized approach. Strongly considered an indication for retirement from future contact \& collision sports \\
\hline Prolonged PCS (>3-6 mos) & $\begin{array}{l}\text { Strongly considered an indication for season-ending retirement. Consider RTP during the following season after } \\
\text { symptomatic recovery, graded aerobic treadmill, \& formal neuropsychological testing }\end{array}$ \\
\hline $\begin{array}{l}\text { Persistent cognitive deficits on for- } \\
\text { mal neuropsychological testing }\end{array}$ & $\begin{array}{l}\text { Individualized approach. Follow-up formal neuropsychological assessment to monitor recovery. Consider } \\
\text { RTP following symptomatic recovery, full return to school participation, \& graded aerobic treadmill \& formal } \\
\text { neuropsychological testing }\end{array}$ \\
\hline Postinjury psychiatric outcomes & $\begin{array}{l}\text { Individualized approach. Must consider preinjury psychiatric history, severity of symptoms, \& neuropsychologi- } \\
\text { cal, aerobic treadmill testing, \& neuroimaging results }\end{array}$ \\
\hline
\end{tabular}

health care professionals who manage pediatric SRC patients. At present, there are no evidence-based guidelines directing the care of pediatric SRC patients with structural brain abnormalities, focal neurological deficits, and abnormalities on physical examination, and those in whom the cumulative or prolonged effects of repetitive brain injury are suspected or demonstrated. Given these limitations, patients in this population are ideally approached by a multidisciplinary team of experts with clinical training and experience in pediatric TBI. In the future, this decision-making process would benefit from the development of novel neuroimaging tools capable of identifying the pathophysiological effects of concussion in individual patients and from research aimed at identifying risk factors associated with the development of adverse short-term outcomes such as PCS, postinjury psychiatric outcomes, and prolonged neurocognitive impairment following pediatric SRC. In addition, prospective and population-based studies are needed to reliably estimate the risk of serious longterm outcomes such as the development of neurodegenerative disease and CTE among child, adolescent, and adult athletes exposed to multiple concussions and repetitive head injury. Until such data are available, RTP and sport retirement decision making regarding children and adolescents must err on the side of caution and we must make every effort to preserve the long-term health of the patient.

\section{References}

1. Al-Holou WN, Yew AY, Boomsaad ZE, Garton HJ, Muraszko KM, Maher CO: Prevalence and natural history of arachnoid cysts in children. J Neurosurg Pediatr 5:578585,2010

2. Allen CR, Kang JD: Transient quadriparesis in the athlete. Clin Sports Med 21:15-27, 2002

3. Alsalaheen BA, Mucha A, Morris LO, Whitney SL, Furman JM, Camiolo-Reddy CE, et al: Vestibular rehabilitation for dizziness and balance disorders after concussion. J Neurol Phys Ther 34:87-93, 2010

4. American Academy of Neurology: Practice parameter: the management of concussion in sports (summary statement). Report of the Quality Standards Subcommittee. Neurology 48:581-585, 1997
5. Babikian T, Freier MC, Tong KA, Nickerson JP, Wall CJ, Holshouser BA, et al: Susceptibility weighted imaging: neuropsychologic outcome and pediatric head injury. Pediatr Neurol 33:184-194, 2005

6. Bailes JE, Hadley MN, Quigley MR, Sonntag VK, Cerullo LJ: Management of athletic injuries of the cervical spine and spinal cord. Neurosurgery 29:491-497, 1991

7. Bailes JE, Petraglia AL, Omalu BI, Nauman E, Talavage $\mathrm{T}$ : Role of subconcussion in repetitive mild traumatic brain injury. J Neurosurg 119:1235-1245, 2013

8. Barlow KM, Crawford S, Stevenson A, Sandhu SS, Belanger F, Dewey D: Epidemiology of postconcussion syndrome in pediatric mild traumatic brain injury. Pediatrics 126:e374-e381, 2010

9. Beauchamp MH, Beare R, Ditchfield M, Coleman L, Babl FE, Kean M, et al: Susceptibility weighted imaging and its relationship to outcome after pediatric traumatic brain injury. Cortex 49:591-598, 2013

10. Blount JP, Severson M, Atkins V, Tubbs RS, Smyth MD, Wellons JC, et al: Sports and pediatric cerebrospinal fluid shunts: who can play? Neurosurgery 54:1190-1198, 2004

11. Bondurant CP, Jimenez DF: Epidemiology of cerebrospinal fluid shunting. Pediatr Neurosurg 23:254-259, 1995

12. Bosch PP, Vogt MT, Ward WT: Pediatric spinal cord injury without radiographic abnormality (SCIWORA): the absence of occult instability and lack of indication for bracing. Spine (Phila Pa 1976) 27:2788-2800, 2002

13. Brown NJ, Mannix RC, O’Brien MJ, Gostine D, Collins MW, Meehan WP III: Effect of cognitive activity level on duration of post-concussion symptoms. Pediatrics 133:e299-e304, 2014

14. Bruce JM, Echemendia RJ: History of multiple self-reported concussions is not associated with reduced cognitive abilities. Neurosurgery 64:100-106, 2009

15. Cantu RC: Posttraumatic retrograde and anterograde amnesia: pathophysiology and implications in grading and safe return to play. J Athl Train 36:244-248, 2001

16. Cantu RC: Recurrent athletic head injury: risks and when to retire. Clin Sports Med 22:593-603, x, 2003

17. Cantu RC: Return to play guidelines after a head injury. Clin Sports Med 17:45-60, 1998

18. Cantu RC, Bailes JE, Wilberger JE Jr: Guidelines for return to contact or collision sport after a cervical spine injury. Clin Sports Med 17:137-146, 1998

19. Cantu RC, Li YM, Abdulhamid M, Chin LS: Return to play after cervical spine injury in sports. Curr Sports Med Rep 12:14-17, 2013 
20. Cantu RC, Register-Mihalik JK: Considerations for returnto-play and retirement decisions after concussion. PM R 3 (10 Suppl 2):S440-S444, 2011

21. Cantu RV, Cantu RC: Guidelines for return to contact sports after transient quadriplegia. J Neurosurg 80:592-594, 1994

22. Collins MW, Lovell MR, Iverson GL, Cantu RC, Maroon JC, Field M: Cumulative effects of concussion in high school athletes. Neurosurgery 51:1175-1181, 2002

23. Concannon LG, Kaufman MS, Herring SA: The million dollar question: When should an athlete retire after concussion? Curr Sports Med Rep 13:365-369, 2014

24. Cook MW, Levin LA, Joseph MP, Pinczower EF: Traumatic optic neuropathy. A meta-analysis. Arch Otolaryngol Head Neck Surg 122:389-392, 1996

25. Corwin DJ, Zonfrillo MR, Master CL, Arbogast KB, Grady MF, Robinson RL, et al: Characteristics of prolonged concussion recovery in a pediatric subspecialty referral population. J Pediatr 165:1207-1215, 2014

26. Cress M, Kestle JR, Holubkov R, Riva-Cambrin J: Risk factors for pediatric arachnoid cyst rupture/hemorrhage: a casecontrol study. Neurosurgery 72:716-722, 2013

27. Cusimano MD, Cho N, Amin K, Shirazi M, McFaull SR, Do MT, et al: Mechanisms of team-sport-related brain injuries in children 5 to 19 years old: opportunities for prevention. PLoS One 8:e58868, 2013

28. Davis G, Marion DW, Le Roux P, Laws ER, McCrory P: Clinics in neurology and neurosurgery - extradural and subdural haematoma. Br J Sports Med 44:1139-1143, 2010

29. Davis GA, Castellani RJ, McCrory P: Neurodegeneration and sport. Neurosurgery 76:643-656, 2015

30. De Marco AP, Broshek DK: Computerized cognitive testing in the management of youth sports-related concussion. $\mathbf{J}$ Child Neurol 31:68-75, 2016

31. Demetriades AK, McEvoy AW, Kitchen ND: Subdural haematoma associated with an arachnoid cyst after repetitive minor heading injury in ball games. Br J Sports Med 38:E8, 2004

32. Echemendia RJ, Herring S, Bailes J: Who should conduct and interpret the neuropsychological assessment in sports-related concussion? Br J Sports Med 43 (Suppl 1):i32-i35, 2009

33. Echemendia RJ, Iverson GL, McCrea M, Broshek DK, Gioia GA, Sautter SW, et al: Role of neuropsychologists in the evaluation and management of sport-related concussion: an inter-organization position statement. Arch Clin Neuropsychol 27:119-122, 2012

34. Eisenberg MA, Meehan WP III, Mannix R: Duration and course of post-concussive symptoms. Pediatrics 133:9991006, 2014

35. Ellis MJ, Cordingley D, Vis S, Reimer K, Leiter J, Russell $\mathrm{K}$ : Vestibulo-ocular dysfunction in pediatric sports-related concussion. J Neurosurg Pediatr 16:248-255, 2015

36. Ellis MJ, Figley CR, Mutch WA, Massicotte E, Mikulis DJ, Essig M, et al: Neuroimaging in sports-related concussion management: current status and future directions. Curr Res Concussion 1:33-39, 2014

37. Ellis MJ, Leddy JJ, Willer B: Physiological, vestibuloocular and cervicogenic post-concussion disorders: an evidence-based classification system with directions for treatment. Brain Inj 29:238-248, 2015

38. Ellis MJ, Leiter J, Hall T, McDonald PJ, Sawyer S, Silver $\mathrm{N}$, et al: Neuroimaging findings in pediatric sports-related concussion. J Neurosurg Pediatr 16:241-247, 2015

39. Ellis MJ, McDonald PJ: Coexistent sports-related concussion and cervical SCIWORA in an adolescent: a case report. Curr Sports Med Rep 14:20-22, 2015

40. Ellis MJ, Ritchie L, Cordingley D, Essig M, Mansouri B: Traumatic optic neuropathy: a potentially unrecognized diagnosis after sports-related concussion. Curr Sports Med Rep 15:27-32, 2016
41. Ellis MJ, Ritchie LJ, Koltek M, Hosain S, Cordingley D, Chu S, et al: Psychiatric outcomes after pediatric sportsrelated concussion. J Neurosurg Pediatr 16:709-718, 2015

42. Ford RL, Lee V, Xing W, Bunce C: A 2-year prospective surveillance of pediatric traumatic optic neuropathy in the United Kingdom. J AAPOS 16:413-417, 2012

43. Gardner A: The complex clinical issues involved in an athlete's decision to retire from collision sport due to multiple concussions: a case study of a professional athlete. Front Neurol 4:141, 2013

44. Gardner A, Iverson GL, McCrory P: Chronic traumatic encephalopathy in sport: a systematic review. Br J Sports Med 48:84-90, 2014

45. Giza CC, Hovda DA: The neurometabolic cascade of concussion. J Athl Train 36:228-235, 2001

46. Goldenberg-Cohen N, Miller NR, Repka MX: Traumatic optic neuropathy in children and adolescents. J AAPOS 8:20-27, 2004

47. Grubenhoff JA, Deakyne SJ, Brou L, Bajaj L, Comstock RD, Kirkwood MW: Acute concussion symptom severity and delayed symptom resolution. Pediatrics 134:54-62, 2014

48. Guskiewicz KM, Marshall SW, Bailes J, McCrea M, Cantu $\mathrm{RC}$, Randolph C, et al: Association between recurrent concussion and late-life cognitive impairment in retired professional football players. Neurosurgery 57:719-726, 2005

49. Guskiewicz KM, Marshall SW, Bailes J, McCrea M, Harding HP Jr, Matthews A, et al: Recurrent concussion and risk of depression in retired professional football players. Med Sci Sports Exerc 39:903-909, 2007

50. Guskiewicz KM, McCrea M, Marshall SW, Cantu RC, Randolph C, Barr W, et al: Cumulative effects associated with recurrent concussion in collegiate football players: the NCAA Concussion Study. JAMA 290:2549-2555, 2003

51. Iverson GL: Chronic traumatic encephalopathy and risk of suicide in former athletes. Br J Sports Med 48:162-165, 2014

52. Kawanishi A, Nakayama M, Kadota K: Heading injury precipitating subdural hematoma associated with arachnoid cysts - two case reports. Neurol Med Chir (Tokyo) 39:231-233, 1999

53. Kepler CK, Vaccaro AR: Injuries and abnormalities of the cervical spine and return to play criteria. Clin Sports Med 31:499-508, 2012

54. Kerr ZY, Marshall SW, Harding HP Jr, Guskiewicz KM: Nine-year risk of depression diagnosis increases with increasing self-reported concussions in retired professional football players. Am J Sports Med 40:2206-2212, 2012

55. Kestle JR: Pediatric hydrocephalus: current management. Neurol Clin 21:883-895, vii, 2003

56. Kodsi SR, Younge BR: Acquired oculomotor, trochlear, and abducent cranial nerve palsies in pediatric patients. Am J Ophthalmol 114:568-574, 1992

57. Kontos AP, Elbin RJ, Schatz P, Covassin T, Henry L, Pardini J, et al: A revised factor structure for the post-concussion symptom scale: baseline and postconcussion factors. Am J Sports Med 40:2375-2384, 2012

58. Kuppermann N, Holmes JF, Dayan PS, Hoyle JD Jr, Atabaki SM, Holubkov R, et al: Identification of children at very low risk of clinically-important brain injuries after head trauma: a prospective cohort study. Lancet 374:11601170,2009

59. Kutcher JS, Eckner JT: At-risk populations in sports-related concussion. Curr Sports Med Rep 9:16-20, 2010

60. Langlois JA, Rutland-Brown W, Wald MM: The epidemiology and impact of traumatic brain injury: a brief overview. J Head Trauma Rehabil 21:375-378, 2006

61. Lau BC, Kontos AP, Collins MW, Mucha A, Lovell MR: Which on-field signs/symptoms predict protracted recovery 
from sport-related concussion among high school football players? Am J Sports Med 39:2311-2318, 2011

62. Lehman EJ, Hein MJ, Baron SL, Gersic CM: Neurodegenerative causes of death among retired National Football League players. Neurology 79:1970-1974, 2012

63. Mahapatra AK, Tandon DA: Traumatic optic neuropathy in children: a prospective study. Pediatr Neurosurg 19:34 39, 1993

64. Makdissi M, Davis G, Jordan B, Patricios J, Purcell L, Putukian M: Revisiting the modifiers: how should the evaluation and management of acute concussions differ in specific groups? Br J Sports Med 47:314-320, 2013

65. Maroon JC, Winkelman R, Bost J, Amos A, Mathyssek $\mathrm{C}$, Miele V: Chronic traumatic encephalopathy in contact sports: a systematic review of all reported pathological cases. PLoS One 10:e0117338, 2015

66. McCrory P: When to retire after concussion? Br J Sports Med 35:380-382, 2001

67. McCrory P, Davis G, Makdissi M: Second impact syndrome or cerebral swelling after sporting head injury. Curr Sports Med Rep 11:21-23, 2012

68. McCrory P, Meeuwisse W, Johnston K, Dvorak J, Aubry M, Molloy M, et al: Consensus Statement on Concussion in Sport: the 3rd International Conference on Concussion in Sport held in Zurich, November 2008. Br J Sports Med 43 (Suppl 1):i76-i90, 2009

69. McCrory P, Meeuwisse WH, Aubry M, Cantu B, Dvorák J, Echemendia RJ, et al: Consensus statement on concussion in sport: the 4th International Conference on Concussion in Sport held in Zurich, November 2012. Br J Sports Med 47:250-258, 2013

70. McKee AC, Cantu RC, Nowinski CJ, Hedley-Whyte ET, Gavett BE, Budson AE, et al: Chronic traumatic encephalopathy in athletes: progressive tauopathy after repetitive head injury. J Neuropathol Exp Neurol 68:709-735, 2009

71. McKee AC, Stern RA, Nowinski CJ, Stein TD, Alvarez VE, Daneshvar DH, et al: The spectrum of disease in chronic traumatic encephalopathy. Brain 136:43-64, 2013

72. Meehan WP III, Jordaan M, Prabhu SP, Carew L, Mannix RC, Proctor MR: Risk of athletes with Chiari malformations suffering catastrophic injuries during sports participation is low. Clin J Sport Med 25:133-137, 2015

73. Meehan WP III, Mannix R: Pediatric concussions in United States emergency departments in the years 2002 to 2006. J Pediatr 157:889-893, 2010

74. Meehan WP III, Mannix R, Monuteaux MC, Stein CJ, Bachur RG: Early symptom burden predicts recovery after sport-related concussion. Neurology 83:2204-2210, 2014

75. Meehan WP III, Mannix RC, Stracciolini A, Elbin RJ, Collins MW: Symptom severity predicts prolonged recovery after sport-related concussion, but age and amnesia do not. J Pediatr 163:721-725, 2013

76. Miele VJ, Bailes JE, Martin NA: Participation in contact or collision sports in athletes with epilepsy, genetic risk factors, structural brain lesions, or history of craniotomy. Neurosurg Focus 21(4):E9, 2006

77. Morgan CD, Zuckerman SL, Lee YM, King L, Beaird S, Sills AK, et al: Predictors of postconcussion syndrome after sports-related concussion in young athletes: a matched casecontrol study. J Neurosurg Pediatr 15:589-598, 2015

78. Moser RS, Iverson GL, Echemendia RJ, Lovell MR, Schatz $\mathrm{P}$, Webbe FM, et al: Neuropsychological evaluation in the diagnosis and management of sports-related concussion. Arch Clin Neuropsychol 22:909-916, 2007

79. Mutch WA, Ellis MJ, Ryner LN, Ruth Graham M, Dufault $\mathrm{B}$, Gregson B, et al: Brain magnetic resonance imaging $\mathrm{CO} 2$ stress testing in adolescent postconcussion syndrome. J Neurosurg [epub ahead of print December 18, 2015. DOI: $10.3171 / 2015.6 . J N S 15972]$
80. Omalu B: Chronic traumatic encephalopathy. Prog Neurol Surg 28:38-49, 2014

81. Osenbach RK, Menezes AH: Pediatric spinal cord and vertebral column injury. Neurosurgery 30:385-390, 1992

82. Osmond MH, Klassen TP, Wells GA, Correll R, Jarvis A, Joubert G, et al: CATCH: a clinical decision rule for the use of computed tomography in children with minor head injury. CMAJ 182:341-348, 2010

83. Pang D: Spinal cord injury without radiographic abnormality in children, 2 decades later. Neurosurgery 55:13251343,2004

84. Pang D, Pollack IF: Spinal cord injury without radiographic abnormality in children - the SCIWORA syndrome. J Trauma 29:654-664, 1989

85. Paulus S, Kennedy DJ: Return to play considerations for cervical spine injuries in athletes. Phys Med Rehabil Clin N Am 25:723-733, 2014

86. Pollack IF, Pang D, Sclabassi R: Recurrent spinal cord injury without radiographic abnormalities in children. J Neurosurg 69:177-182, 1988

87. Prabhu VC, Bailes JE: Chronic subdural hematoma complicating arachnoid cyst secondary to soccer-related head injury: case report. Neurosurgery 50:195-198, 2002

88. Richards BW, Jones FR Jr, Younge BR: Causes and prognosis in 4,278 cases of paralysis of the oculomotor, trochlear, and abducens cranial nerves. Am J Ophthalmol 113:489-496, 1992

89. Rihn JA, Anderson DT, Lamb K, Deluca PF, Bata A, Marchetto PA, et al: Cervical spine injuries in American football. Sports Med 39:697-708, 2009

90. Ritchie LJ, Mrazik M, Alfano DP, Chase D, Comprer P, Czarnota M, et al: The role of neuropsychology in the management of youth concussion in Canada. Curr Res Concussion 2:8-9, 2015

91. Saigal R, Batjer HH, Ellenbogen RG, Berger MS: Return to play for neurosurgical patients. World Neurosurg 82:485491,2014

92. Schneider KJ, Meeuwisse WH, Nettel-Aguirre A, Barlow $\mathrm{K}$, Boyd L, Kang J, et al: Cervicovestibular rehabilitation in sport-related concussion: a randomised controlled trial. Br J Sports Med 48:1294-1298, 2014

93. Sedney CL, Orphanos J, Bailes JE: When to consider retiring an athlete after sports-related concussion. Clin Sports Med 30:189-200, xi, 2011

94. Solomon GS, Zuckerman SL: Chronic traumatic encephalopathy in professional sports: Retrospective and prospective views. Brain Inj 29:164-170, 2015

95. Steinsapir KD, Goldberg RA: Traumatic optic neuropathy. Surv Ophthalmol 38:487-518, 1994

96. Stern RA, Daneshvar DH, Baugh CM, Seichepine DR, Montenigro PH, Riley DO, et al: Clinical presentation of chronic traumatic encephalopathy. Neurology 81:11221129,2013

97. Stern RA, Riley DO, Daneshvar DH, Nowinski CJ, Cantu RC, McKee AC: Long-term consequences of repetitive brain trauma: chronic traumatic encephalopathy. PM R 3 (10 Suppl 2):S460-S467, 2011

98. Talavage TM, Nauman EA, Breedlove EL, Yoruk U, Dye AE, Morigaki KE, et al: Functionally-detected cognitive impairment in high school football players without clinically-diagnosed concussion. J Neurotrauma 31:327-338, 2014

99. Tator $\mathrm{CH}$ : Chronic traumatic encephalopathy: how serious a sports problem is it? Br J Sports Med 48:81-83, 2014

100. Tator $\mathrm{CH}$ : Concussions and their consequences: current diagnosis, management and prevention. CMAJ 185:975979,2013

101. Tempel ZJ, Bost JW, Norwig JA, Maroon JC: Significance of T2 hyperintensity on magnetic resonance imaging after 
cervical cord injury and return to play in professional athletes. Neurosurgery 77:23-31, 2015

102. Thorndike A: Serious recurrent injuries of athletes; contraindications to further competitive participation. N Engl J Med 247:554-556, 1952

103. Tong KA, Ashwal S, Holshouser BA, Nickerson JP, Wall CJ, Shutter LA, et al: Diffuse axonal injury in children: clinical correlation with hemorrhagic lesions. Ann Neurol 56:36-50, 2004

104. Torg JS: Cervical spine injuries and the return to football. Sports Health 1:376-383, 2009

105. Torg JS, Corcoran TA, Thibault LE, Pavlov H, Sennett BJ, Naranja RJ Jr, et al: Cervical cord neurapraxia: classification, pathomechanics, morbidity, and management guidelines. J Neurosurg 87:843-850, 1997

106. Torg JS, Naranja RJ Jr, Pavlov H, Galinat BJ, Warren R, Stine RA: The relationship of developmental narrowing of the cervical spinal canal to reversible and irreversible injury of the cervical spinal cord in football players. J Bone Joint Surg Am 78: 1308-1314, 1996

107. Torg JS, Ramsey-Emrhein JA: Cervical spine and brachial plexus injuries: return-to-play recommendations. Phys Sportsmed 25:61-88, 1997

108. Torg JS, Ramsey-Emrhein JA: Management guidelines for participation in collision activities with congenital, developmental, or post-injury lesions involving the cervical spine. Clin Sports Med 16:501-530, 1997

109. Torg JS, Ramsey-Emrhein JA: Management guidelines for participation in collision activities with congenital, developmental, or postinjury lesions involving the cervical spine. Clin J Sport Med 7:273-291, 1997

110. Tsuzuki N, Katoh H, Ohtani N: Chronic subdural hematoma complicating arachnoid cyst secondary to soccer-related head injury: case report. Neurosurgery 53:242-243, 2003
111. Tubbs RS, Krishnamurthy S, Verma K, Shoja MM, Loukas $\mathrm{M}$, Mortazavi MM, et al: Cavum velum interpositum, cavum septum pellucidum, and cavum vergae: a review. Childs Nerv Syst 27:1927-1930, 2011

112. White AA III, Johnson RM, Panjabi MM, Southwick WO: Biomechanical analysis of clinical stability in the cervical spine. Clin Orthop Relat Res (109):85-96, 1975

113. Wippold FJ II: Focal neurologic deficit. AJNR Am J Neuroradiol 29:1998-2000, 2008

114. Yuh EL, Hawryluk GW, Manley GT: Imaging concussion: a review. Neurosurgery 75 (Suppl 4):S50-S63, 2014

115. Zuckerman SL, Kuhn A, Dewan MC, Morone PJ, Forbes JA, Solomon GS, et al: Structural brain injury in sportsrelated concussion. Neurosurg Focus 33(6):E6, 1-12, 2012

\section{Disclosures}

The authors report no conflict of interest concerning the materials or methods used in this study or the findings specified in this paper.

\section{Author Contributions}

Conception and design: Ellis, McDonald, Ritchie. Acquisition of data: all authors. Analysis and interpretation of data: all authors. Drafting the article: Ellis, McDonald, Ritchie. Critically revising the article: all authors. Reviewed submitted version of manuscript: all authors. Approved the final version of the manuscript on behalf of all authors: Ellis.

\section{Correspondence}

Michael Ellis, Pan Am Clinic, 75 Poseidon Bay, Winnipeg, MB R3M 3E4, Canada. email: mellis3@panamclinic.com. 